\title{
Acrophobia and Gender - A Case Study on Government High School Students, Guntur District, Andhra Pradesh, India
} Sankara Pitchaiah Podila

Department of Geology, Acharya Nagarjuna University, Andhra Pradesh, India

\begin{abstract}
Acrophobia is a an irrational fear of heights. The phobia is classified by space and motion discomfort, this fear has many root causes and can be severe in its intensity. The present study was carried out to know the degree of the acrophobia among 8th to 10th Government high school students. The response was taken from 2743 students (Male: 1589. Female: 1154). The study found that out of the total male students, $21.63 \%$ students expressed the phobia and it is $16.99 \%$ in the case of female. Comparatively, high percentage of male students has acrophobia than female students in all the classes. Homeopathy, Exposure based therapy, Cognitive therapy and Relaxation techniques are some of the useful treatment methods.
\end{abstract}

Keywords :Acrophobia, Treatment, Male and Female, High School Students

\section{INTRODUCTION}

\section{METHODOLOGY}

A phobia is a type of anxiety disorder, defined by a persistent and excessive fear of an object or situation. The phobia typically results in a rapid onset of fear and is present for more than six months (American Psychiatric Association, 2013). Specific phobias were studied by Ollendick et al., (2010); Curtis et al., (1998); de Oliveira-Souza (2018); Naveed et al., (2015); Pull (2008) Singh and Singh (2016).

Acrophobic behavior typically involves the avoidance of a variety of height-related situations, including stairs, terraces, apartments and offices located in high buildings, bridges, elevators and plane trips (Menzies, 1997). Symptoms include panic, rapid breathing, nausea or vertigo.

The present study was carried out to know the degree of Acrophobia among $8^{\text {th }}$ to $10^{\text {th }}$ class male and female students, studying Government high schools.

$8^{\text {th }}$ to $10^{\text {th }}$ class students were chosen as subjects. A total of 2743 students from 10 Government high schools was participated out of them 1589 are male and 1154 were female. The details are shown in Tables 1 and 2. Students were assembled in a classroom of the respective schools and asked them to give their response to a single question-"Do you have a fear of heights?" The purpose of the study and the details regarding the phobia were explained in their mother tongue. The response was analyzed using statistical analysis. Percent variation was observed and presented under results and discussion. 
TABLE 1 -SCHOOL WISE, CLASS WISE AND GENDER WISE STUDENT'S STRENGTH

\begin{tabular}{|l|c|c|c|c|c|c|c|c|c|}
\hline \multicolumn{1}{|c|}{ Classes $\rightarrow$} & \multicolumn{3}{|c|}{ 8th } & \multicolumn{3}{c|}{ 9th } & \multicolumn{3}{c|}{ 10th } \\
\hline \multicolumn{1}{|c}{ Schools } & Male & Female & Total & Male & Female & Total & Male & Female & Total \\
\hline Ponnekallu & 52 & 40 & 92 & 36 & 42 & 78 & 49 & 40 & 89 \\
\hline Takkellapadu & 27 & 37 & 64 & 25 & 22 & 47 & 24 & 23 & 47 \\
\hline Venigalla & 33 & 52 & 85 & 31 & 37 & 68 & 48 & 55 & 103 \\
\hline Koppuravuru & 40 & 36 & 76 & 39 & 28 & 67 & 30 & 23 & 53 \\
\hline SK & 104 & 75 & 179 & 106 & 54 & 160 & 118 & 70 & 188 \\
\hline SJRR & 80 & 53 & 133 & 78 & 47 & 125 & 48 & 45 & 93 \\
\hline SKS & 55 & 45 & 100 & 46 & 48 & 94 & 67 & 51 & 118 \\
\hline P & 75 & 17 & 92 & 62 & 21 & 83 & 57 & 20 & 77 \\
\hline KSR & 26 & 26 & 52 & 62 & 17 & 79 & 30 & 26 & 56 \\
\hline SCMP & 54 & 39 & 93 & 40 & 36 & 76 & 47 & 29 & 76 \\
\hline Total & 546 & 420 & 966 & 525 & 352 & 877 & 518 & 382 & 900 \\
\hline
\end{tabular}

TABLE 2 SCHOOL WISE AND GENDER WISE STUDENT, WITH ACROPHOBIA

\begin{tabular}{|l|c|c|c|c|c|c|}
\hline \multicolumn{1}{|c|}{ Classes $\rightarrow$} & \multicolumn{2}{c|}{ 8th } & \multicolumn{2}{c|}{ 9th } & \multicolumn{2}{c|}{ 10th } \\
\hline \multicolumn{1}{|c|}{ Schools } & Male & Female & Male & Female & Male & Female \\
\hline Ponnekallu & 11 & 9 & 11 & 8 & 28 & 27 \\
\hline Takkellapadu & 4 & 3 & 3 & 3 & 2 & 6 \\
\hline Venigalla & 5 & 11 & 4 & 5 & 9 & 7 \\
\hline Koppuravuru & 4 & 3 & 7 & 4 & 2 & 0 \\
\hline SK & 39 & 22 & 38 & 7 & 37 & 8 \\
\hline SJRR & 19 & 16 & 24 & 16 & 14 & 13 \\
\hline SKS & 14 & 12 & 9 & 18 & 21 & 18 \\
\hline P & 25 & 6 & 17 & 7 & 1 & 0 \\
\hline KSR & 3 & 2 & 12 & 2 & 6 & 1 \\
\hline SCMP & 5 & 4 & 11 & 8 & 9 & 10 \\
\hline Total & 129 & 88 & 136 & 78 & 129 & 90 \\
\hline
\end{tabular}

\section{RESULTS AND DISCUSSION}

A percent variation of the male and female students, those suffering from Acrophobia was shown in table 3 and figures 1 and 2 .

\section{Male}

$8^{\text {th }}$ class

Highest percent of $\mathrm{P}$ school students (27.17) were marked the Acrophobia (Figure 1A), followed by SK
(21.79\%), SJRR (14.29\%). The lowest percent was noticed with Koppuravuru (5.26\%).

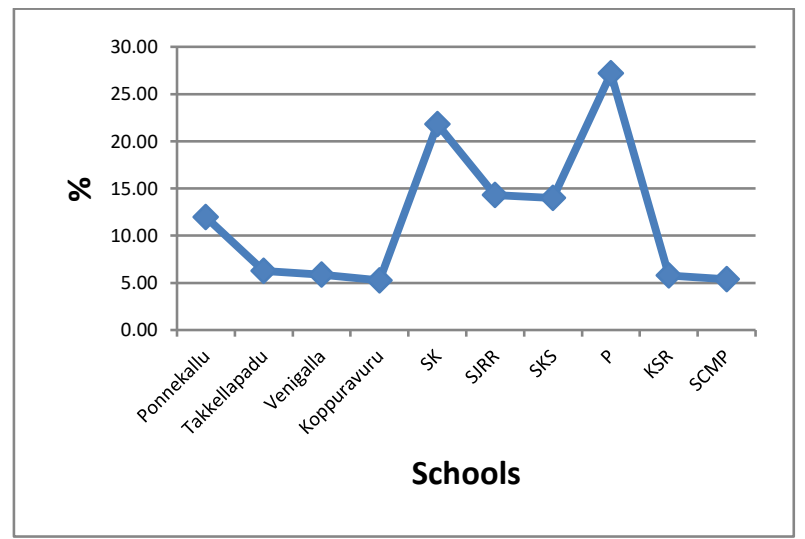

Figure 1A. $-8^{\text {th }}$ Male Students with Acrophobia 
$9^{\text {th }}$ Class

$23.75 \%$ of SK school students had expressed the Acrophobia (Figure 1B), followed by Pschool students (20.48\%) and SJRR (19.20\%). Comparatively, the problem is low in Venigalla (5.88\%).

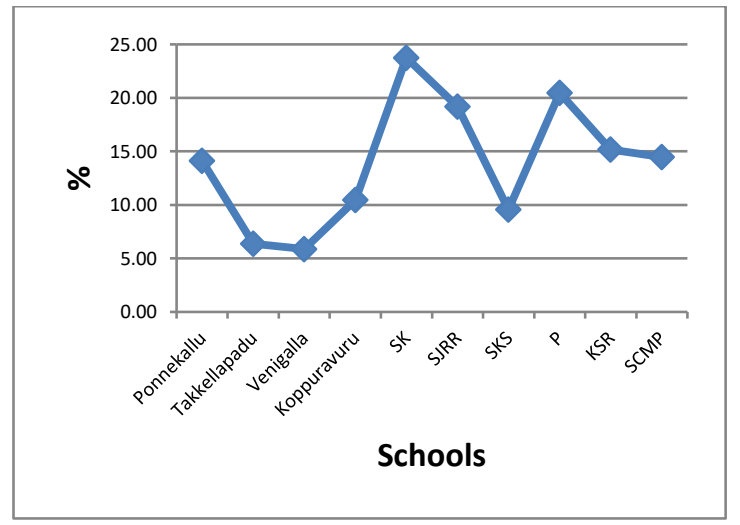

Figure 1B -9th Male Students with Acrophobia

\section{$10^{\text {th }}$ Class}

Highest percent of Ponnekallu students (31.46) were marked the Acrophobia (Figure 1C), followed by SK (19.68\%) and SKS (17.80\%). The problem is low in $\mathrm{P}$ $(1.30 \%)$.

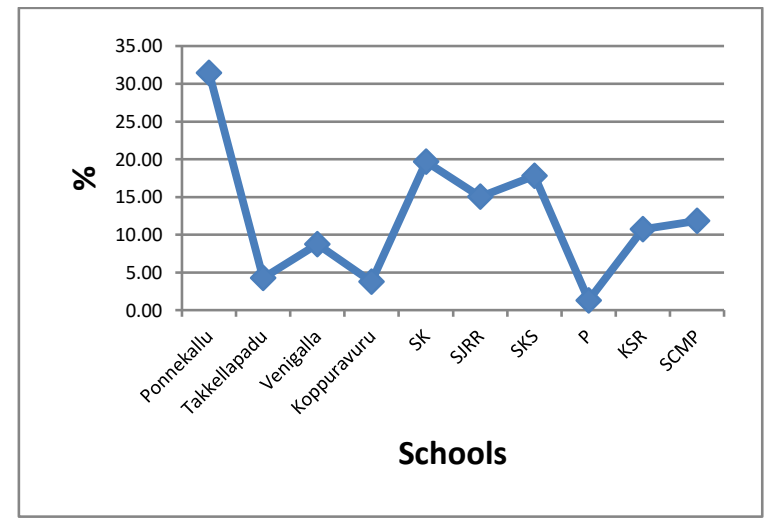

Figure 1C. $-10^{\text {th }}$ Male Students with Acrophobia

As the $10^{\text {th }}$ class marks/grades are important for future studies, the comparatively higher percentage with phobia were recorded with most of the schools for male students.

\section{Female}

$8^{\text {th }}$ Class

$12.94 \%$ of Venigalla students were pointed Acrophobia (Figure 2A), followed by SK (12.29\%) and SJRR (12.03\%). The lowest percent was observed with KSR (3.85\%).

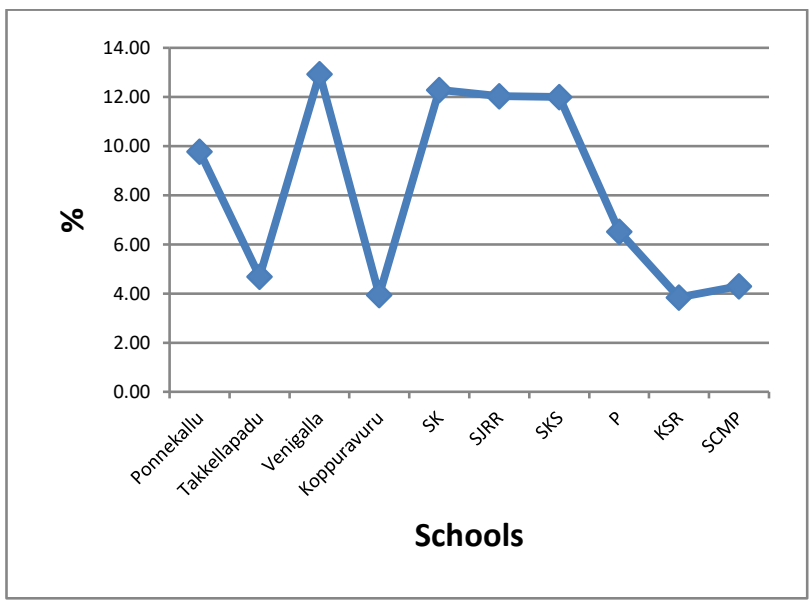

Figure 2A. $-8^{\text {th }}$ Female Students with Acrophobia

$9^{\text {th }}$ Class

Highest percent of SKS (19.15) school students had Acrophobia (Figure 2B), followed by SJRR (12.80\%) and SCMP (10.53\%). The lowest percent was observed in KSR students (2.53\%).

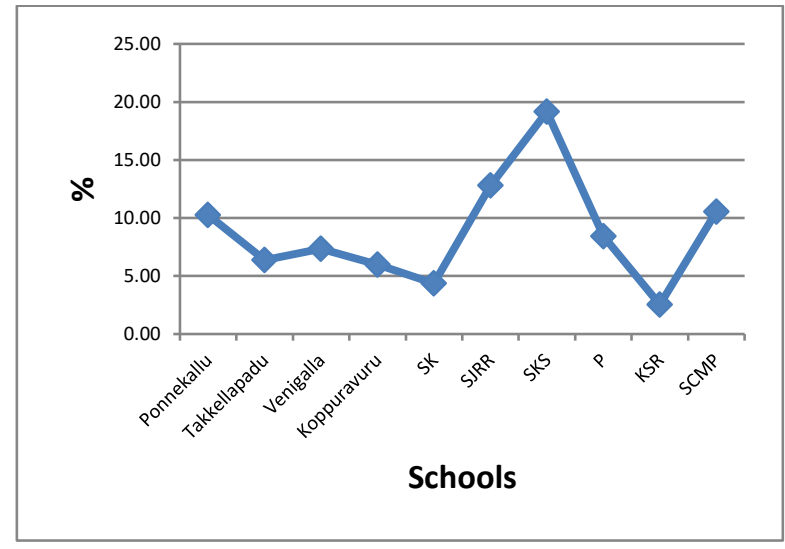

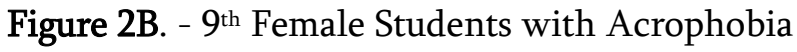

$10^{\text {th }}$ Class

$30.34 \%$ of Ponnekallu students were suffering from Acrophobia (Figure 2C), followed by SKS (15.25\%) and SJRR (13.98\%). No student was expressed the phobia from Koppuravuru and P schools. 


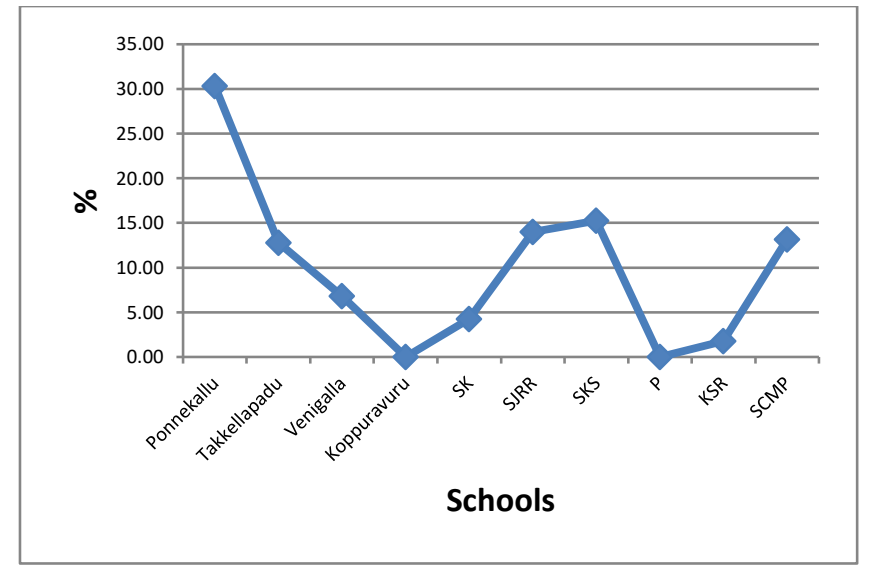

Figure 2C. $-10^{\text {th }}$ Female Students with Acrophobia

\section{Comparative study}

\section{Male $\left(8^{\text {th }}\right.$ to $\left.10^{\text {th }}\right)$}

Comparison of Acrophobia among $8^{\text {th }}$ to $10^{\text {th }}$ class of male students was shown in table 3 and figure 3). Among the male students, high percent of
Ponnekallu 10 $10^{\text {th }}$ students (31.46\%) had Acrophobia followed by P (27.17\%), and SK (23.75\%). The lowest percent was observed with $\mathrm{P}, 10^{\text {th }}$ class students $(1.30 \%)$.

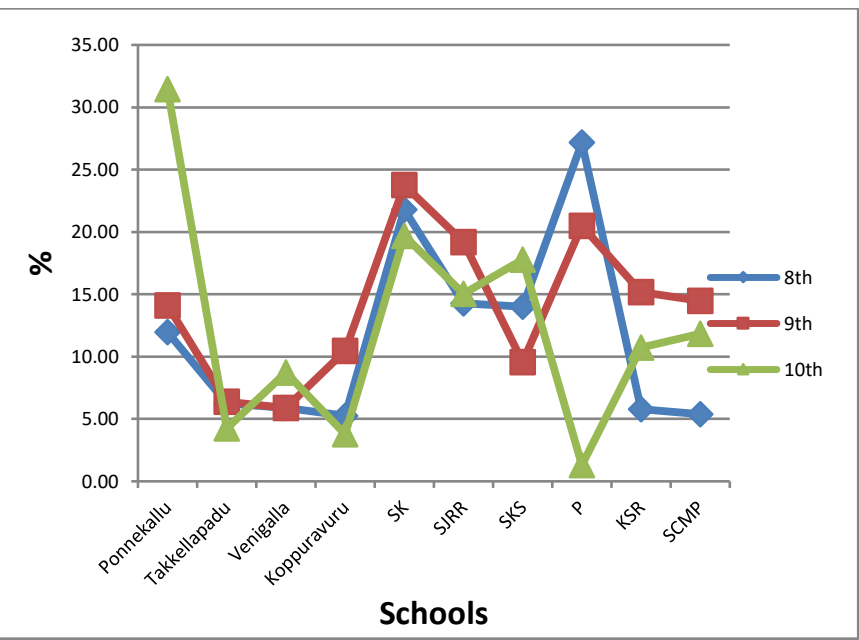

Figure $3.8^{\text {th }}$ to $10^{\text {th }}$ class male students with Acrophobia

TABLE 3 PERCENTAGE OF MALE AND FEMALE STUDENTS WITH ACROPHOBIA

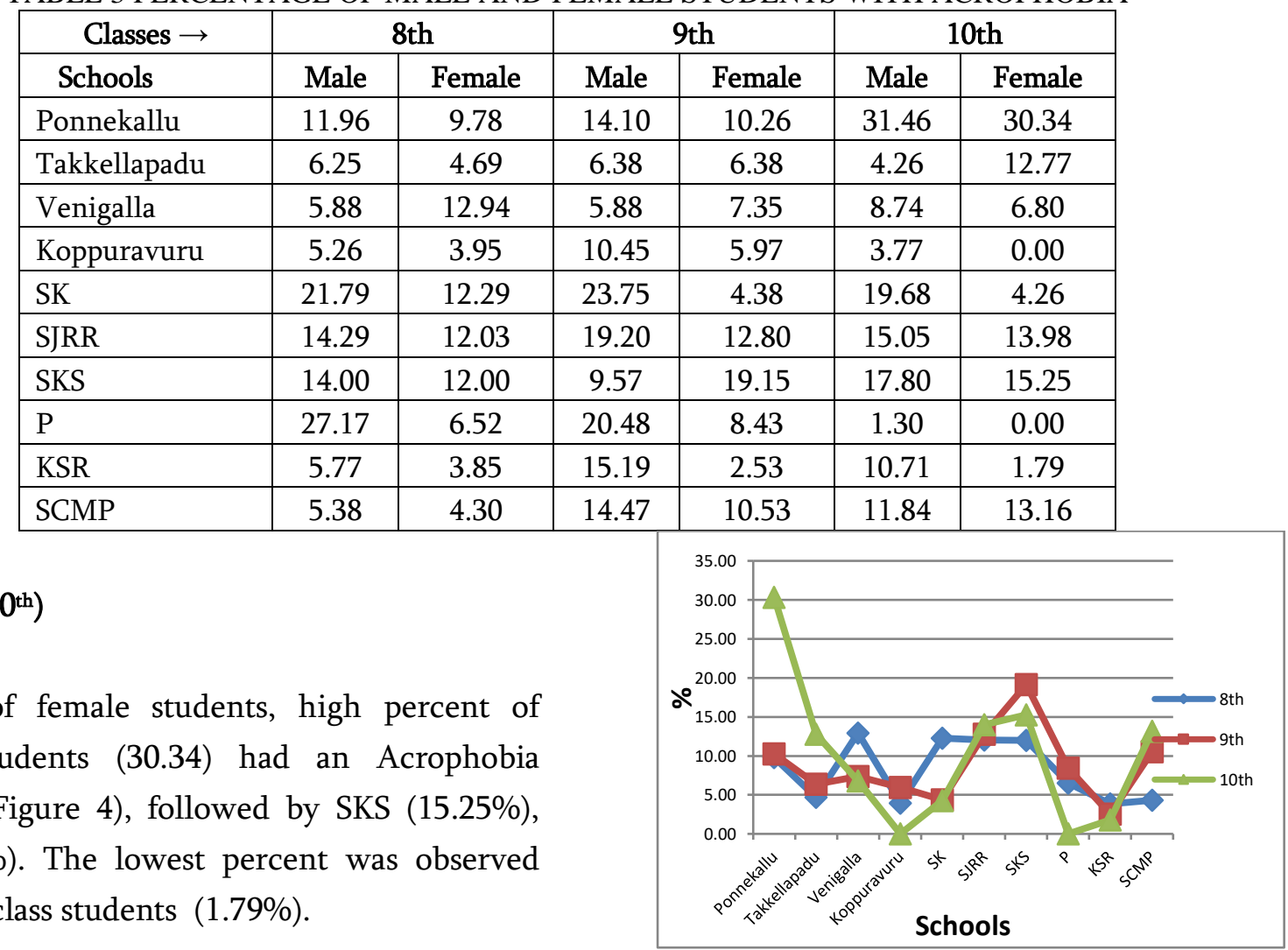

Figure $4.8^{\text {th }}$ to $10^{\text {th }}$ class Female students with Acrophobia 


\section{Comparison of Acrophobia between Male and Female}

Comparison of Acrophobia among $8^{\text {th }}$ to $10^{\text {th }}$ class male students was shown in table 4 and figure 5). Highest percent of SK (21.63) had expressed acrophobia, followed by Ponnekallu (19.31\%) and P (17.06\%). The lowest percent was observed with Takkellapadu (5.70\%). In the case of female students, highest percent of Ponnekallu (16.99) had chosen, followed by SKS (15.38\%) and SJRR (12.82\%). The lowest percentage was observed with KSR (2.67\%).

TABLE 4 COMPARISON OF ACROPHOBIA BETWEEN MALE AND FEMALE STUDENTS (\%)

\begin{tabular}{|l|c|c|}
\hline \multicolumn{1}{|c|}{ Schools } & Male & Female \\
\hline Ponnekallu & 19.31 & 16.99 \\
\hline Takkellapadu & 5.70 & 7.59 \\
\hline Venigalla & 7.03 & 8.98 \\
\hline Koppuravuru & 6.63 & 3.57 \\
\hline SK & 21.63 & 7.02 \\
\hline SJRR & 16.24 & 12.82 \\
\hline SKS & 14.10 & 15.38 \\
\hline P & 17.06 & 5.16 \\
\hline KSR & 11.23 & 2.67 \\
\hline SCMP & 10.20 & 8.98 \\
\hline
\end{tabular}

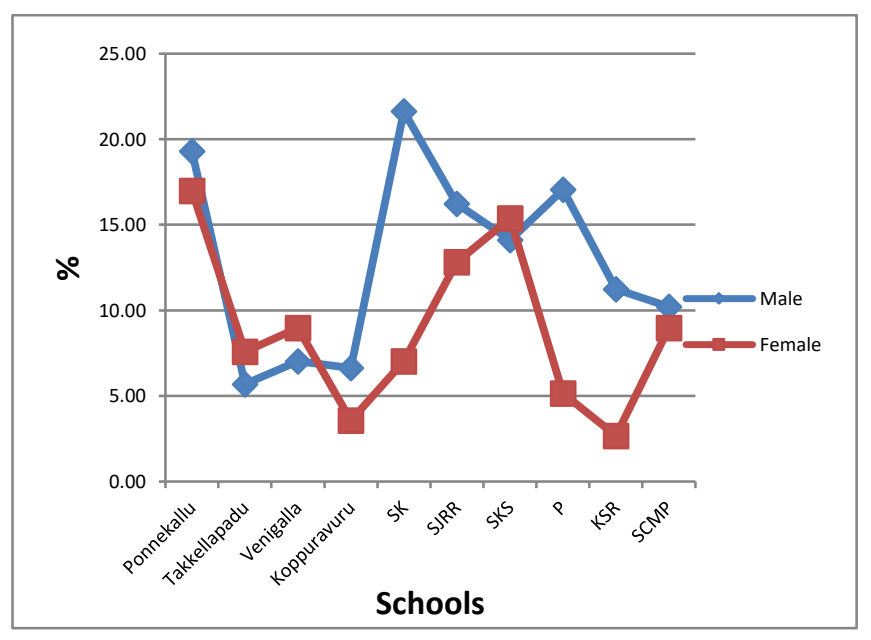

Figure 5. Acrophobia among $8^{\text {th }}$ to $10^{\text {th }}$ class male and female students
Coelho, and Wallis (2010) found that the fear of heights is an expression of a largely sensory phenomena, which can produce strong feelings of discomfort and fear in the otherwise calm individuals. Specific phobias have a high prevalence rate in epidemiological data, both in adolescents (Essau, Conradt, \&Petermann, 2000) and in adults (Boyd et al., 1990).

Fear of flying increased as a function of age in women (Fredrikson, 1996). Huppert and Brandt (2015) examined three primary schools on the frequency of visual height intolerance in 455 children aged 8 to 10 years. They concluded that more than one third of prepubertal girls and boys exhibited susceptibility for visual height intolerance. The present study found that Acrophobia was more in male compared to female students.

\section{Treatment Methods}

There are certain therapies by which this phobia is treatable. Cause of Acrophobia may be any traumatic experience involving heights are hereditary. The main treatment of choice for specific phobias is Cognitive-behavioral (CBT). Behavioral techniques by which survivor is exposed to feared situations (gradually or rapidly) are frequently used. In addition, the patient is taught ways of stopping the panic reaction and regaining emotional control (Abbas and Kiran, 2015).

Virtual reality (VR) technology has been used in the psychological treatment of acrophobia since 1995. Virtual reality exposure therapy (VRET) has been shown to be as effective as traditional forms of in vivo exposure therapy for the treatment of specific phobias. However, as with in vivo exposure, VRET still involves relatively high costs and limited accessibility which makes it prohibitive for a large part of the population. Innovative methods using smart phone applications (apps) may improve accessibility and scalability of VRET. Donker et al., 
(2018) evaluated OPhobia, a gamified self-guided VRET for acrophobia that is delivered through a smartphone app in combination with rudimentary cardboard virtual reality (VR) goggles. Brandt et al., (2018) studied about Susceptibility to Fear of Heights in Bilateral Vestibulopathy and Other Disorders of Vertigo and Balance.

Traditionally, actual exposure to heights is the most ordinary solution. However, there have been a number of research studies into using virtual reality as a treatment for acrophobia. A major benefit of virtual reality treatment is the savings in both cost and time, as there is no need for "on-location" therapist accompaniment. More research will need to be carried on before this method becomes a readily available option, but if it is available it may be worth trying (Bouman et al., 1992).

Because some individuals who fear heights have often been unable to report a clear height related aversive experience as a primary etiological factor, some authors have proposed hereditary or non-associative accounts in the disorder's development (Menzies \& Clarke, 1993, 1995a). In one study, Menzies and Clarke (1993) compared fearful and non-fearful participants' responses to heights in an attempt to assess their acquisition of height-related fear. A few years later, Menzies and Clarke (1995b) were able to extend these findings using a much larger clinically defined group of acrophobics. All this evidence led the authors to rule out a latent inhibition hypothesis (e.g. Bond \&Siddle, 1996; Lubow, 1973).

\section{Some of the useful methods}

Exposure-based therapy - (Singh and Singh, 2016)

Cognitive therapy (CT)- (Specific phobia. http://www. med.upenn.edu).

Progressive desensitization (Specific phobia. http://www. med.upenn.edu).

Relaxation- (Specific phobia. http://www. med.upenn.edu).
Hypnosis (hypnotherapy)- (Natural treatment for phobia and anxiety. http://www.phobicss-ociety.org) Homeopathy- (http:// www.phobicssociety .org).

Herbal remedies- (Natural treatment for phobia and anxiety. http:// www.phobicssociety.org).

\section{CONCLUSION}

Acrophobia is a type of specific phobia and is an extreme fear of heights. The present study made a comparison of the phobia among $8^{\text {th }}$ to $10^{\text {th }}$ male and female students. Out of the total 1589 male students 394 students have acrophobia. Similarly, in the case of female students, 256 students out of 1154 expressed the phobia. State Government shall find the suitable mechanism to assess the specific phobias among the students and to treat the phobias.

\section{ACKNOWLEDGEMENT}

Authors are thankful to Rotary club - Adharsh, Guntur Commissioner, GMC and the Authorities of Acharya Nagarjuna University for the financial assistance.

\section{REFERENCES}

[1]. Abbas Syeda Sarah and Kiran Sehrish (2015), People With Fear Of Height; Acrophobia, World Journal Of Pharmaceutical And Medical Research, 1(1), 52-5.

[2]. American Psychiatric Association (2013), Diagnostic and Statistical Manual of Mental Disorders (5th ed.), Arlington: American Psychiatric Publishing, 190, 197-202.

[3]. Bond, N., \& Siddle, D. A. (1996), The preparedness account of social phobia: some data and alternative explanations. In: R. M. Rapee (Ed.), Current Controversies in the Anxiety Disorders (291-316). London: Guilford Press. 
[4]. Bouman, K., Scholing, A., Emmelkamp, P.M.G.(1992), Anxiety Disorders: A Practitioners Guide,John Wiley \& Sons.

[5]. Boyd, J. H., Rae, D. S., Thompson, J. W., Burns, B. J., Bourdon, K., Locke, B. Z., et al. (1990), Phobia: prevalence and risk factors. Social psychiatry and psychiatric epidemiology, 25, 314-323.

[6]. Brandt T, Grill E, Strupp M and Huppert D (2018) Susceptibility to Fear of Heights in Bilateral Vestibulopathy and Other Disorders of Vertigo and Balance. Front. Neurol. 9:406. doi: 10.3389/fneur.2018.00406

[7]. Coelho C. M., and Wallis Guy (2010), Deconstructing Acrophobia: Physiological And Psychological Precursors To Developing A Fear Of Heights, Depression And Anxiety $27: 864-870$.

[8]. Curtis G C, Magee W J, Eaton WW, Wittchen H U and Kessler RC (1998), The British Journal of Psychiatry, 173:212-217.

[9]. de Oliveira-Souza R (2018), Phobia of the Supernatural: A Distinct but Poorly Recognized Specific Phobia With an Adverse Impact on Daily Living. Front. Psychiatry 9:590.

[10]. Donker T., S. Van Esveld, N. Fischer and A. Van Straten (2018), OPhobia - towards a virtual cure for acrophobia: study protocol for a randomized controlled trial, Trials, 19:433.

[11]. Essau, C. A., Conradt, J., \& Petermann, F. (2000), Frequency, comorbility, and psychosocial impairment of specific phobia in adolescents. Journal of Clinical Child Psychology, 29(2), 221-231.

[12]. Fredrikson M, Annas P, Fischer A and Wik G (1996) Gender and age differences in the Prevalence of specific fears and phobias, Behav. Res. Ther., Vol.34, No.1, pp. 33-39.

[13]. Huppert D, Brandt T (2015) Fear of Heights and Visual Height Intolerance in Children 8-
10 Years Old. J Child Adolesc Behav 3: 219. doi:10.4172/2375-4494.1000219

[14]. Lubow, R. E. (1973), Latent inhibition. Psychological Bulletin, 79(6), 398-407.

[15]. Menzies RG (1997), Height Phobia. In: Davey GLC, editor. Phobias. A Handbook of Theory, Research and Treatment. Chichester: Wiley;:129-138.

[16]. Menzies, R. G., \& Clarke, J. C. (1993), The etiology of fear of heights and its relationship to severity and individual response patterns. Behaviour Research and Therapy, 31(4), 355365.

[17]. Menzies, R. G., \& Clarke, J. C. (1995a), The etiology of fear acrophobia and its relationship to severity and individual response patterns. Behaviour research and therapy, 33(7), 795-803.

[18]. Menzies, R. G., \& Clarke, J. C. (1995b), The etiology of acrophobia and its relationship to severity and individual-response patterns. Behaviour Research and Therapy, 33(7), 795803.

[19]. Natural treatment for phobia and anxiety. Available at http:// www.phobicssociety .org.uk/natural treatment for phobia and anxiety/ Accessed on 24 December 2015.onal Journal of Basic \& C.

[20]. Naveed S, Sana A, Rehman H, Qamar F, Abbas SS, et al. (2015) Prevalence and Consequences of PHOBIAS, Survey Based Study in Karachi. J Bioequiv Availab 7: 140143.

[21]. Ollendick Thomas H., Natoshia Raishevich, Thompson E. Davis III, Cristian Sirbu, LarsGöran Öst (2010) Phenomenology and Psychological Characteristics, Behavior Therapy 41, 133-141.

[22]. Pull Charles B. (208) Recent trends in the study of specific phobias, Curr Opin Psychiatry 21:43-50. 
[23]. Singh Jarnail, Singh Janardhan (2016) Treatment options for the specific phobias Int J Basic Clin Pharmacol, ;5(3):593-598.

[24]. Specific phobia. Available at http://www. med.upenn.edu/csta /phoias_treatment. html. Accessed on 26 December 2015.

Cite this article as :

Sankara Pitchaiah Podila, "Acrophobia and Gender A Case Study on Government High School Students, Guntur District, Andhra Pradesh, India", International Journal of Scientific Research in Science and Technology (IJSRST), Online ISSN : 2395-602X, Print ISSN : 2395-6011, Volume 6 Issue 1, pp. 219-226, January-February 2019. Available at doi:https://doi.org/10.32628/IJSRST196135 Journal URL : http://ijsrst.com/IJSRST196135 